\title{
Vaccine-associated paralytic poliomyelitis in Brazil, 1989-1995
}

\author{
Lúcia Helena de Oliveira ${ }^{1}$ and Claudio José Struchiner ${ }^{2}$
}

\begin{abstract}
At the present time, the only poliovirus-caused poliomyelitis cases reported in Brazil and other countries of the Americas are of vaccine etiology. It is important for epidemiological surveillance and immunization programs to evaluate the epidemiological profile of cases of vaccineassociated paralytic poliomyelitis (VAPP) in order to establish criteria for case definition and vaccination strategies. To research VAPP in Brazil, 30 cases diagnosed and classified as such by the Ministry of Health between 1989 and 1995 were submitted to a descriptive study of clinical, laboratory, and epidemiological data. In addition, the risk of occurrence of VAPP was estimated in relation to determinants based on a cohort of 3656 persons with acute flaccid paralysis.

Among individuals who had received oral polio vaccine (OPV) from 4 to 40 days before the onset of paralysis, we found a relative risk of 8.88 (95\% CI: 4.37-18.03) for VAPP as compared with persons who had not been vaccinated during the same time interval. For individuals who developed VAPP in the period following national vaccination days, the estimated relative risk was 2.94 (95\% CI: 1.44-6.00). For the first dose of OPV administered to the general population the estimated risk was 1 case of VAPP for every 2.39 million doses; for total doses of $O P V$ the risk was 1 case in 13.03 million doses. A major share of VAPP cases were related to children affected by prodromes (fever and gastrointestinal signs and/or symptoms), isolation of vaccine poliovirus type 2, paralysis of the lower limbs, and a mean age of 1 year.
\end{abstract}

Circulation of indigenous wild poliovirus had been stopped in Brazil and other countries of the Americas, the International Commission for the Certification of Poliomyelitis Eradication concluded in 1994 after analyzing epidemiological and immunization data (1). At the present time, the only

\footnotetext{
1 Brazil, Ministry of Health, National Foundation for Health, Professor Hélio Fraga Reference Center, Rio de Janeiro, RJ, Brazil.

2 Brazil, Ministry of Health, Oswaldo Cruz Foundation, National School of Public Health, Rio de Janeiro, Brazil, and State University of Rio de Janeiro, Institute for Social Medicine, Rio de Janeiro, RJ, Brazil. Address correspondence to: Claudio Struchiner, Av. Brasil 4365, Residencia Oficial (PROCC), Rio de Janeiro, RJ, Brazil, CEP 21045-900; e-mail: stru@malaria.procc.fiocruz.br
}

poliomyelitis cases occurring in the Region of the Americas are of vaccine origin (2). Although the attenuated strains of the oral poliovirus vaccine (OPV) can revert to neurovirulence, the occurrence of vaccine-associated poliomyelitis (VAPP) cases is rare. VAPP cases can occur among both vaccine recipients and their contacts (3). Other than immunodeficiency, there are no conditions that pinpoint those at greater risk of VAPP (2). Cases of VAPP in Brazil and other countries are most likely to be caused by the poliovirus type 2 and type 3 strains (4). In addition, recent studies have confirmed isolation of poliovirus type 1 from VAPP cases and have also shown the occurrence of mutations in the samples (5).

VAPP cases were first observed immediately after introduction of the attenuated live poliovirus vaccines in the 1960s. In the United States of America during 1980-1994 the risk of VAPP was approximately 1 case for every 2.4 million doses of OPV distributed. This risk has remained relatively constant since 1965. It is estimated that the first OPV dose triggers 1 case of VAPP for every 750000 doses (6). For immunodeficient persons the risk is believed to be 7 to 21 times higher with the first dose than with subsequent OPV doses (2).

Up until 1989 in Brazil, cases classified as VAPP included: 1) acute flaccid 
paralysis with neurological sequelae compatible with poliomyelitis 60 days after the impairment of motor function had begun, 2) vaccine poliovirus isolated from samples of feces, and 3) a history of vaccination 4 to 30 days before the onset of paralysis. Beginning in 1990, the patient's vaccination record was eliminated as one of the criteria. This was done because VAPP cases can also occur in unvaccinated contacts; isolation of vaccine poliovirus should be considered in feces samples collected up to 14 days after the onset of paralysis, according to a conference presentation by Freitas et al. ${ }^{3}$

The aim of this study was to estimate the risk of VAPP in Brazil associated with the first and subsequent doses of OPV, and to assess whether or not the chances of developing the disease are greater for children exposed to a larger number of OPV doses. We carried out a descriptive analysis to characterize VAPP cases in Brazil. Beginning with a cohort of individuals with acute flaccid paralysis, we analyzed the possibility of intramuscular injections as a determinant for the occurrence of VAPP.

\section{MATERIALS AND METHODS}

In Brazil, VAPP cases are detected after the presence of acute flaccid paralysis is reported to the epidemiological surveillance system of the poliomyelitis eradication program of the Ministry of Health (Freitas conference presentation). For our research, we studied a cohort of 3656 patients with acute flaccid paralysis of the extremities, 30 of whom had been classified as VAPP cases, reported to the Ministry of Health, and included in the Poliomyelitis Eradication Surveillance System of the Pan American Health Organization (PAHO) between 1989 and 1995. Among all of the acute

\footnotetext{
3 Freitas H, Oliveira LH, Pedreira MC, Silva SR. Análise de casos de poliomielite associados à vacina notificados ao Ministério da Saúde 89/93 [conference presentation]. III Congresso Brasileiro, II Congresso Ibero-Americano, I Congresso LatinoAmericano de Epidemiologia. Salvador, Bahia, Brasil, 1994.
}

paralysis cases, only 20 occurred in persons older than 15 years of age.

A National Commission to Review Poliomyelitis Cases classified the acute flaccid paralysis cases as vaccine-associated poliomyelitis according to the following two criteria: 1 ) cases of acute flaccid paralysis with sequelae compatible with poliomyelitis 60 days after impairment of motor function had begun and 2) vaccine poliovirus isolated from feces collected up to 14 days after onset of the impairment (in certain cases, the Commission could extend this period). These cases were evaluated by neurologists, and in the vast majority of the cases electromyography yielded results compatible with damage to the anterior horn of the spinal cord.

We present a descriptive analysis of VAPP cases resulting from: 1) exposure to OPV between 4 and 40 days before the beginning of acute flaccid paralysis, which is to say recipients of the vaccine (7), and 2) exposure to national vaccination days, that is, persons presenting acute flaccid paralysis from 4 to 40 days after a vaccination campaign. We also analyzed the following variables: gender, fever, respiratory and gastrointestinal signs and/ or symptoms, paralyzed limbs, number of doses received before motor function impairment, type of vaccine poliovirus isolated, and previous intramuscular injections. For intramuscular injections, only cases of acute flaccid paralysis from 1992 and later were considered, as this information was not available for earlier years.

We calculated the mean, variance, and standard deviation of age of VAPP cases and of other acute flaccid paralysis cases. To check for homogeneity of variances between VAPP and nonVAAP groups, we used Bartlett's test. Once the test rejected the null hypothesis, indicating heterogeneous variances, we used the Kruskal-Wallis test to check for equality of means, comparing the VAPP cases with the remaining cases of flaccid paralysis $(8,9)$.

We estimated the risk of VAPP occurrence in relation to the first dose as well as to all the OPV doses received. In addition, we calculated the raw rel- ative risk (RR) of VAPP in paralysis cases for the covariables of exposure to $\mathrm{OPV}$, exposure to national vaccination days, and exposure to intramuscular injections.

We used multivariate logistic regression analysis to assess the risk of VAPP occurrence among persons with a history of OPV vaccination or of intramuscular injections. We also used multivariate analysis to calculate the risk of VAPP among subjects who had both acute flaccid paralysis 4 to 40 days after national vaccination days and a history of intramuscular injections. The logistic regression model produced estimated odd ratios as measures of association. For each of the variables in the model we calculated the regression coefficient, standard error, and confidence interval. Model comparison was performed via likelihood tests (10). Our statistical analyses used 95\% confidence intervals and a 5\% alpha error (9-11). We used two statistical software programs, Epi Info version 6.04b (U.S. Centers for Disease Control and Prevention, Atlanta, Georgia, United States of America) and S-PLUS version 3.3 (MathSoft, Inc., Cambridge, Massachusetts, United States).

\section{RESULTS}

Among a cohort totaling 3656 cases of acute flaccid paralysis, 2314 of the persons $(63.3 \%)$ had received at least one dose of OPV, 190 individuals $(5.2 \%)$ had not been vaccinated, and no information was available for the remaining 1152 persons (31.5\%). From a total of 30 VAPP cases, $23(76.7 \%)$ had been vaccinated, $3(10.0 \%)$ had not been vaccinated, and for the 4 others $(13.3 \%)$ that information was not known (Table 1).

Table 2 shows that among the clinical manifestations preceding paralysis, fever was the most common variable, followed by gastrointestinal signs or symptoms (vomiting, diarrhea, or constipation). Vaccine poliovirus type 2 accounted for the greatest percentage of isolates, followed by type 3 . If grouped together, all the isolates that included poliovirus 2 strains would 
TABLE 1. Acute flaccid paralysis (AFP) cases classified as vaccineassociated paralytic poliomyelitis (VAPP) or not and the number of doses of oral poliovirus vaccine (OPV) received

\begin{tabular}{lrrrrrr}
\hline & \multicolumn{2}{c}{ VAPP } & & \multicolumn{2}{c}{ Non-VAPP } \\
\cline { 2 - 3 } \cline { 6 - 6 } \multicolumn{1}{c}{ OPV doses } & No. & $\%$ & & & No. & $\%$ \\
\hline Zero doses & 3 & 10.00 & & 187 & 5.16 \\
One dose & 8 & 26.67 & & 227 & 6.26 \\
Two doses & 7 & 23.33 & & 125 & 3.45 \\
Three or more doses & 8 & 26.67 & & 1939 & 53.47 \\
Information not known & 4 & 13.33 & & 1148 & 31.66 \\
$\quad$ Total & 30 & 100.00 & & 3626 & 100.00 \\
\hline
\end{tabular}

TABLE 2. Variables associated with the 30 cases of vaccine-associated paralytic poliomyelitis (VAPP)

\begin{tabular}{|c|c|c|}
\hline \multirow[b]{2}{*}{ Variable } & \multicolumn{2}{|c|}{ VAPP } \\
\hline & No. & $\%$ \\
\hline OPVa & 14 & 46.7 \\
\hline National vaccination days ${ }^{b}$ & 14 & 46.7 \\
\hline Male & 13 & 43.3 \\
\hline Fever & 26 & 86.7 \\
\hline Gastrointestinal signs and symptoms & 20 & 66.7 \\
\hline Respiratory signs and symptoms ${ }^{c}$ & $3^{c}$ & $27.3^{\mathrm{c}}$ \\
\hline Poliovirus 1 & 2 & 6.7 \\
\hline Poliovirus 2 & 11 & 36.7 \\
\hline Poliovirus 3 & 8 & 26.7 \\
\hline Poliovirus 1, 3 & 1 & 3.3 \\
\hline Poliovirus 2, 3 & 3 & 10.0 \\
\hline Poliovirus 1, 2, 3 & 5 & 16.7 \\
\hline Lower extremity & 16 & 53.3 \\
\hline Lower extremities & 3 & 10.0 \\
\hline Triplegia & 2 & 6.7 \\
\hline Quadriplegia & 4 & 13.3 \\
\hline Otherd ${ }^{d}$ & 5 & 16.7 \\
\hline Intramuscular injections ${ }^{c}$ & $5^{c}$ & $45.5^{\mathrm{c}}$ \\
\hline
\end{tabular}

a Individuals who received oral poliovirus vaccine 4 to 40 days before onset of paralysis.

${ }^{\mathrm{b}}$ Individuals who developed paralysis 4 to 40 days after national vaccination days.

${ }^{c}$ Cases from 1992 on.

${ }^{d}$ Acute flaccid paralysis (AFP) of the extremities and/or respiratory and/or facial AFP or hemiplegia.

TABLE 3. Age (years) of VAPP cases and of other cases of acute flaccid paralysis (AFP)

\begin{tabular}{lcr}
\hline & VAPP & Other AFP \\
\hline Mean & 1.07 & 5.40 \\
Variance & 3.14 & 19.23 \\
Standard deviation & 1.78 & 4.38 \\
\hline
\end{tabular}

Bartlett's $\chi^{2}=26.93$ (degrees of freedom $=1 ; P$ value $<0.01$ ). Kruskal-Wallis $\chi^{2}=42.21$ (degrees of freedom $=1 ; P$ value $<0.01$ ).

Seventy-five percent of the VAPP cases occurred among children under 1 year of age, and the maximum age was 8 years. When we stratified the age variable into two groups, under 1 year and 1 year and older, the risk of VAPP occurrence was found to be 15 times higher for the younger group.

Overall for the period investigated, the study found a risk of 1 VAPP case per 2.39 million first doses of OPV and 1 case per 13.03 million of the total doses administered. Table 4 presents the estimated relative risks for VAPP among recipients of OPV, subjects who developed paralysis following national vaccination days, and subjects who received intramuscular injections.

In Table 5 the risk from having been exposed to OPV is adjusted according to the history of intramuscular injections. This risk is lower than was found with the raw risk presented above.

Adjusting the model to include two variables, exposure to vaccination campaigns and exposure to intramuscular injections, shows a loss of statistical significance for the first of the variables (Table 6).

\section{DISCUSSION}

encompass $63.4 \%$ of all the cases. Paralysis was predominantly located in the lower extremities (in one or both limbs). Fourteen of the 30 VAPP cases were classified as exposed to the vaccine; the same number of cases occurred in the periods following national vaccination days. Only $43.3 \%$ of the cases were males.

Analysis of VAPP cases in relation to the rest of AFP cases showed different age ranges. Bartlett's test suggested heterogeneity between age variances. Given that result, we applied the Kruskal-Wallis nonparametric test and found heterogeneity of age groupings between the VAPP cases and the other subjects with acute flaccid paralysis (Table 3).

For the VAPP cases, the median age was under 1 year; the median for the rest of the observations was 4 years.
Our results confirm data published in the international literature insofar as the low risk of VAPP is concerned. In Brazil, however, risks and incidences appear to be even lower than those found in other studies. Other research points to an estimated risk of 1 case for every 750000 first doses in the United States (6) and of around 1 case 
TABLE 4. Unadjusted estimated relative risk (RR) for VAPP, after exposure to the oral poliovirus vaccine, national vaccination days, and intramuscular injections

\begin{tabular}{lccc}
\hline \multirow{2}{*}{ Variable } & \multicolumn{3}{c}{ VAPP } \\
\cline { 2 - 4 } & $\mathrm{RR}$ & $95 \% \mathrm{Cl}$ & $P$ value \\
\hline Oral poliovirus vaccine $^{\mathrm{a}}$ & 8.88 & $4.37-18.03$ & $<0.01$ \\
National vaccination days $^{\mathrm{b}}$ & 2.94 & $1.44-6.00$ & $<0.01$ \\
Intramuscular injection $^{\mathrm{c}}$ & 6.37 & $1.97-20.64$ & $<0.01$ \\
\hline
\end{tabular}

a Individuals who received OPV 4 to 40 days before onset of paralysis.

${ }^{b}$ Individuals who developed paralysis 4 to 40 days after national vaccination days.

c Cases from 1992 on.

TABLE 5. Relative risk for VAPP occurrence estimated by multivariate logistic regression (odds ratio), with exposure to oral poliovirus vaccine adjusted for history of intramuscular injections

\begin{tabular}{cccccc}
\hline Variable & Odds ratio & $95 \% \mathrm{Cl}$ & Coefficient & Standard error & $P$ value \\
\hline Oral poliovirus vaccine & 6.58 & $1.94-22.29$ & 1.88 & 0.62 & $<0.01$ \\
Intramuscular injection & 5.15 & $1.52-17.43$ & 1.63 & 0.62 & $<0.01$ \\
\hline
\end{tabular}

TABLE 6. Relative risk for VAPP occurrence estimated by multivariate logistic regression (odds ratio), with model adjusted for exposure to national vaccination days and intramuscular injection

\begin{tabular}{lccccc}
\hline \multicolumn{1}{c}{ Variable } & Odds ratio & \multicolumn{1}{c}{$95 \% \mathrm{Cl}$} & Coefficient & Standard error & $P$ value \\
\hline National vaccination days & 2.03 & $0.59-7.00$ & 0.71 & 0.63 & 0.26 \\
Intramuscular injection & 6.46 & $1.95-21.35$ & 1.86 & 0.61 & $<0.01$ \\
\hline
\end{tabular}

for every 2.5 million total OPV doses distributed (12-14). In our study, the findings were 1 case for every 2.39 million first doses and 1 case for every 13.03 million total doses administered. Even when our data are compared with a study carried out in Latin America that included information on Brazil (15), the risks of developing VAPP with the first dose and with the total doses of OPV are much lower.

The Brazilian VAPP cases came from a cohort of acute flaccid paralysis patients. These patients were followed up by the poliomyelitis eradication program of the Ministry of Health. The guidelines for the program allowed inclusion of any and all patients with acute flaccid paralysis, whatever the where isolation of vaccine poliovirus was required within 15 days of the onset of motor impairment.

Another factor to keep in mind is that national vaccination campaigns have been implemented in Brazil since 1980, with wide dissemination of vaccine poliovirus among the population. It is to be assumed that, at the time cases were being analyzed, older individuals would already have had several opportunities to be in contact with vaccine poliovirus and probably to be immunized. In third world countries with hot climates, frequent vaccination campaigns could be undermining the reduction of poliovirus seroconversion, in a manner similar to the interference posed by diarrheal diseases as described in various studies $(3,16-21)$.

With respect to isolation of vaccine poliovirus, our results agreed with the published literature in finding that poliovirus types 2 and 3 were the most common strains in cases associated with the vaccine. Type 1 is considered to be more stable during the attenuation/virulence process $(4,12,22)$.

Our analysis showed a significant association between VAPP occurrence and previous exposure to the vaccine. In other words, individuals exposed to the vaccine had a significantly higher risk of VAPP than did those not vaccinated 4 to 40 days before the onset of motor impairment. In the literature reviewed, VAPP risk estimates are limited by the fact that most studies present data on exposure or nonexposure to the vaccine as percentages. Even given that limitation, those other results are still consistent with the results we found in Brazil. Some studies indicate that the majority of VAPP cases occur among vaccine recipients, rather than their contacts $(6,13,23-25)$. Other researchers, however, have found the opposite, with the majority of cases occurring among contacts of vaccine recipients $(12,25,26)$.

We also found an association in Brazil between VAPP cases and children who had acute flaccid paralysis following national vaccination days. It should be noted that all the children vaccinated (whether they had a vaccination card or not) were classified as 
"exposed to national vaccination days," and so were their contacts, since this association is characterized by the time period of possible transmission and not by the history of vaccines received.

As for age of VAPP occurrence in Brazil, cases were concentrated among younger persons. Seventy-five percent of the cases occurred among children under 1 year of age, and the mean age was 1 year. These findings agree with the literature pointing to a majority of cases in the youngest age groups (12, $25,27)$. At the same time, we observed a lower percentage of cases among male children in comparison to studies from other countries where this variable was assessed $(12,23,27)$.

A large percentage of the Brazilian VAPP cases presented prodromal fever and gastrointestinal signs and/or symptoms. Since this variable was not analyzed in the other literature we reviewed, we could not compare our results with those of other researchers. Nevertheless, one study indicates that a "minor illness" characterized by fever, vomiting, and diarrhea is one of the clinical manifestations of poliomyelitis (28). By itself, this description allows our findings to be considered relevant in cases of paralytic poliomyelitis.

We found that over $60 \%$ of the VAPP cases had paralysis of one or both lower extremities. Our finding agrees with a study by Strebel et al. (29) that showed a greater risk of VAPP when motor impairment was localized in one or both lower extremities.

We found that a history of intramuscular (IM) injections was an important risk factor for VAPP. Our finding is consistent with some previous studies based on the assumption of a phenomenon called "provoked poliomyelitis" (30). A case-control study done in Ro- mania showed this association to be very strong, and the authors concluded that the high rates of VAPP found in that country could be explained by the large number of antibiotic injections given to children with febrile diseases (29). However, an ecological study carried out in the United States found that intramuscular antibiotic or vaccine injections did not seem to contribute to the VAPP risk in recipients of the oral vaccine (31). It is essential to point out some aspects of the VAPP-IM association in Brazil that point to the need to view those results with some caution. It was not possible to determine the exact dates on which the Brazilian children were given intramuscular injections; whether the injected substance was an antibiotic, a vaccine, or something else; or the number of injections administered close to the onset of flaccid paralysis. That lack of information seriously limits the interpretation of our findings in that area.

Another important aspect to consider is the administration of multiple vaccinations on Brazilian national vaccination days. The question is, would there be an increased risk of VAPP on vaccination days when oral vaccines are given at the same time as injected vaccines? Our results do not suggest that the administration of intramuscular injections along with exposure to national vaccination campaigns increases the risk for VAPP. In our construction of a logistic regression model including those two variables, exposure to national vaccination days loses its statistical significance. When we adjusted our model for the effects of exposure to OPV (vaccine recipients) and a history of intramuscular injections, the risk value for both variables diminished in relation to the raw relative risk, thus confirming our previous analysis. Taking into account the aforementioned limitations to this analysis, it would be interesting to carry out future studies in which this hypothesis could be tested, for instance, in a controlled study of a cohort of children receiving OPV, with specific information on dates and substances administered via intramuscular injections.

Most of our findings confirm study results published in other literature, even after consideration of aspects that limit comparison. Therefore, based on the results of our descriptive analysis and some possible determinants of VAPP occurrence, we suggest that special attention to the possibility of a VAPP diagnosis be given to young children presenting with acute flaccid paralysis, recent vaccination with OPV, prodromal symptoms, motor impairment of the lower extremities, isolation of poliovirus 2 or 3 strains, or a history of intramuscular injections, as well as the occurrence of acute flaccid paralysis in the periods following vaccination campaigns.

Acknowledgments. The authors extend special thanks to Dr. Luiz Antônio Bastos de Camacho (Oswaldo Cruz Foundation, Ministry of Health, Brazil) and Dr. João Baptista Risi Junior (Pan American Health Organization, PWR/ Brazil). We also acknowledge with gratitude the support provided for the study by the National Epidemiology Center of the National Health Foundation of the Ministry of Health of Brazil. Claudio J. Struchiner was partially funded by CNPq, PRONEX/FINEP, and FAPERJ.

\section{REFERENCES}

1. Pan American Health Organization. Third Meeting of the International Commission for the Certification of Poliomyelitis Eradication. Washington, D.C.: PAHO, Expanded Program on Immunization; 1994.

2. Advisory Committee on Immunization Practices. Poliomyelitis prevention in the United States: introduction of a sequential vaccina- tion schedule of inactivated poliovirus vaccine followed by oral poliovirus vaccine. Recommendations of the Advisory Committee on Immunization Practices. Morb Mortal Wkly Rep 1997;46(RR-3):1-25.

3. Melnick JL. Advantages and disadvantages of killed and live poliomyelitis vaccines. Bull World Health Organ 1978;56(1):21-38.
4. Friedrich F, Filippis AMB, Ferreira FC, Schatzmayr HG, Da Silva EE. Genomic characterization of type 1 Sabin-related polioviruses isolated in Brazil. Acta Virol 1995; 39(1):23-29.

5. Furione M, Guillot S, Otelea D, Balanant J, Candrea A, Crainic R. Polioviruses with natural recombinant genomes isolated from 
vaccine-associated paralytic poliomyelitis. Virology 1993:196(1):199-208.

6. Centers for Disease Control and Prevention. Paralytic poliomyelitis-United States, 19801994. Morb Mortal Wkly Rep 1997;46(4): 79-83.

7. Pan American Health Organization. Polio eradication field guide. 2nd ed. Washington, D.C.: PAHO; 1994. p. 9-11.

8. Epi Info, versão 6, guia do usuário [Portuguese edition of: U.S. Centers for Disease Control and Prevention. Epi Info, version 6. Atlanta, Georgia: CDC.] Brasil: Ministério da Saúde; 1994

9. Milton JS, Tsokos JO. Statistical methods in the biological and health sciences. New York: McGraw-Hill; 1983.

10. Kleinbaun DG. Logistic regression: a self-learning text. New York: Springer-Verlag; 1994.

11. Hosmer DW, Lemeshow L. Applied logistic regression. New York: John Willey \& Sons; 1989.

12. Nkowane BM, Wassilak SGF, Orenstein WA. Vaccine-associated paralytic poliomyelitis. JAMA 1987;257(10):1335-1340.

13. Strebel PM, Sutter RW, Cochi SL, Biellik RJ, Brink EW, Kew OM, et al. Epidemiology of poliomyelitis in the United States one decade after the last reported case of indigenous wild virus-associated disease. Clin Infect Dis 1992; 14(2):568-579.

14. Prevots RD, Sutter RW, Strebel PM, Weibel RE, Cochi SL. Completeness of reporting for paralytic poliomyelitis, United States, 1980 through 1991. Arch Pediatr Adolesc Med 1994;148(5):479-485.

15. Andrus JK, Strebel PM, De Quadros CA, Olivé JM. Risk of vaccine-associated paralytic poliomyelitis in Latin America, 1989-1991. Bull World Health Organ 1995;73(1):33-40.

16. Salk J. Experiência com a vacina de poliovírus inativados: comparação entre vacinas de po- liovírus inativados e atenuados. A Saúde no Brasil (Ministério da Saúde do Brasil) 1983; 1(1):21-25.

17. Ghendon Y. WHO recommendation on potential use of new poliomyelitis vaccines. Dev Biol Stand 1993;78:133-139.

18. World Health Organization Collaborative Study Group on Oral Poliovirus Vaccine. Factors affecting the immunogenicity of oral poliovirus vaccine: a prospective evaluation in Brazil and Gambia. J Infect Dis 1995;171(5): 1097-1106.

19. Posey DL, Linkins RW, Oliveira MJ, Monteiro D, Patriarca PA. The effect of diarrhea on oral poliovirus vaccine failure in Brazil. J Infect Dis 1997;175(suppl 1):S258-S263.

20. Myaux JA, Unicomb L, Besser RE, Modlin JF, Uzma A, Islan AM, et al. Effect of diarrhea on the humoral response to oral polio vaccination. Pediatr Infect Dis J 1996;15(3):204-209.

21. Maldonado YA, Cruz-Penã V, Sanches ML, Logan L, Blandón S, Cantwell MF, et al. Host and viral factors affecting the decreased immunogenicity of Sabin type 3 vaccine after administration of trivalent oral polio vaccine to rural Mayan children. J Infect Dis 1997;175(3): 545-553.

22. Nomoto A. Recombinant polioviruses as candidate strains of oral poliovaccines. Dev Biol Stand 1995;84:123-127.

23. Maass G, Quast U. Acute spinal paralysis after the administration of oral poliomyelitis vaccine in the Federal Republic of Germany (1963-1984). J Biol Stand 1987;15(2):185-191.

24. Joce R, Wood D, Brown D, Begg N. Paralytic poliomyelitis in England and Wales, 19851991. BMJ 1992;305(6845):79-82.

25. Strebel PM, Combiescu AA, Nodelcu-Ion N Moroeanu-Biberi S, Combiescu M, Sutter RW, et al. Paralytic poliomyelitis in Romania, 1984-1992: evidence for a high risk of vaccineassociated disease and reintroduction of wild- virus infection. Am J Epidemiol 1994;40(12): 1111-1124.

26. Querfurth H, Swanson PD. Vaccine-associated paralytic poliomyelitis, regional case series and review. Arch Neurol 1990;47(5): 541-544.

27. Weibel RE, Benor DE. Reporting vaccineassociated paralytic poliomyelitis: concordance between the CDC and National Vaccine Injury Compensation Program. Am J Public Health 1996;86(5):734-737.

28. Cohen JI. Enteroviruses and reoviruses. In: Fauci AS, Braunwald E, Isselbacher KJ Wilson JD, Martin JB, Kasper DL, et al., eds. Principles of internal medicine. 14th ed. New York: McGraw-Hill Companies; 1998. p. 11201121.

29. Strebel PM, Nedelcu-Ion N, Baughman AL, Sutter RW, Cochi SL. Intramuscular injections within 30 days of immunization with oral poliovirus vaccine-a risk factor for vaccineassociated paralytic poliomyelitis. $\mathrm{N}$ Engl J Med 1995;332(8):500-506.

30. Sutter RW, Brink EW, Cochi SI, Kew OM, Orenstein WA, Biellik RJ, et al. A new epidemiologic and laboratory classification system for paralytic poliomyelitis cases. Am J Public Health 1989;79(4):495-498.

31. Izurieta HS, Sutter RW, Baughman A, Strebel PM, Stevenson JM, Wharton M. Vaccineassociated paralytic poliomyelitis in the United States: no evidence of elevated risk after simultaneous intramuscular injections of vaccine. Pediatr Infect Dis 1995;14(10): 840-846.

Manuscript received on 26 March 1999. Revised version accepted for publication on 27 August 1999.

RESUMEN En la actualidad, los únicos casos de poliomielitis por poliovirus descritos en Brasil y en otros países americanos son de etiología vacunal. Para la vigilancia epidemiológica y los programas de inmunización es importante investigar el perfil epidemiológico de los casos de poliomielitis paralítica asociada a la vacuna (PPAV) con el fin de establecer criterios para la definición de los casos y las estrategias de vacunación. Para investigar la PPAV en Brasil, se sometieron a un estudio descriptivo de los datos clínicos, epidemiológicos y de laboratorio 30 casos diagnosticados y clasificados como tal por el Ministerio de Salud entre 1989 y 1995. Además, con base en una cohorte de 3656 personas con parálisis flácida aguda, se estimó el riesgo de ocurrencia de PPAV en función de diferentes variables.

Entre los individuos que recibieron la vacuna oral frente a la poliomielitis (VOP) 4 a 40 días antes del inicio de la parálisis flácida aguda, el riesgo relativo de PPAV fue de 8,88 (intervalo de confianza de 95\%, IC95\%: 4,37 a 18,03), en comparación con las personas que no habían sido vacunadas en el mismo intervalo de tiempo. Para los individuos que contrajeron PPAV en los 4 a 40 días siguientes a una campaña de vacunación nacional, el riesgo relativo estimado fue de 2,94 (IC95\%: 1,44 a 6,00). Para la primera dosis de VOP administrada a la población general el riesgo estimado fue de un caso de PPAV por cada 2,39 millones de dosis; para el total de dosis de VOP, el riesgo fue de un caso por 13,03 millones de dosis. La mayor proporción de casos de PPAV ocurrió en niños con síntomas prodrómicos (fiebre y síntomas o signos gastrointestinales), aislamiento del poliovirus vacunal de tipo 2, parálisis de los miembros inferiores y promedio de un año de edad. 